\title{
Leader is the person who deals with conflict. Global answers in conflict management.
}

\author{
Csilla Kohlhoffer-Mizser, ${ }^{1, *}$ \\ ${ }^{1}$ Óbuda University Keleti Károly Faculty of Business and Management, Hungary
}

\begin{abstract}
Worldwide, leader is the person in an organization who directs, manages and controls at least one person. The purpose of this study is to internationally examine the relationship between leadership decisionmaking and resolution of conflict. Author is aiming to provide a comprehensive global literature review of leadership decision-making and conflict management. Alternative dispute resolution methods are to support persons and expressly leaders with several levels of conflict solving. Author interviewed leaders through a questionnaire survey how they decide in case of conflict: do they prefer court procedure or the possibilities of alternative dispute resolution? From 124 answers the paper's main finding is that leaders prefer alternative dispute resolution if they can choose. Methodology is different regarding the types of leaders from different dimensions, as transformational, transactional, and laissezfaire leader dimensions. This approach treated conflict styles as individual disposition, stable over time and across situations. It is argued and supported by literature that leadership styles or behaviors remain stable over time and are expected to be significantly related to conflict management styles [1]. The Thomas-Kilmann Conflict Mode Instrument (TKI) assesses an individual's behavior in conflict situations, in which we can describe a person's behavior along two basic dimensions: (1) assertiveness, the extent to which the individual attempts to satisfy his or her own concerns, and (2) cooperativeness, the extent to which the individual attempts to satisfy the other person's concerns.
\end{abstract}

\section{Introduction}

This paper aims to be forward-looking in the sense that it emphasizes the importance of leadership styles in conflict, in conflict management, connectivity and peaceful settlement. In trust based relationships liability has a significant role, to be liable for our decisions we may recognized as a profit in society, and look at Alternative Dispute Resolution (ADR) approach as a progress, society is going to focus regarding that this process can bring for the individual as well as for the community the greatest benefit.

Leadership styles can vary from one person to another, and one has to consider that there are no two identical cases, no two identical decisions.

The third part of this paper, data collection aims to show an examination: different management styles and conflict resolution choices are be measured with a questionnaire for

\footnotetext{
*Corresponding author: mizser.csilla@kgk.uni-obuda.hu
} 
managers. Leaders were interviewed, that in case of conflict do they prefer the judiciary procedure or the alternative dispute resolution procedures.

Leadership decisions, the possibilities of settling legal relationships (corporate law disputes, disputes between companies, labour law conflicts, organizational and interorganizational) play an important role in the alternative dispute resolution practice.

Based on trust mediation process is able to work with the parties. Based the process on the principle of trust -even if trust is lost at the moment of the conflict in the relationship of the parties -to work on the basis of trust is necessary to reach an agreement. Several studies work with buyer-seller conflict management, as Celuch et al. ascertain the aim to address how trust interacts with attributions to impact the effect of partner communication on conflict resolution perceptions in buyer-seller relationships [2]. Research examines environments in which agents are randomly matched to play a Prisoner's Dilemma, and each player observes a few of the partner's past actions against previous opponents [3].

Mediation is an opportunity in the subject of the alternative dispute resolution system, as one kind of procedures to solve a conflict. Mediation is based on the voluntary participation of the parties. Mediation is a procedure, in which an intermediary without adjudicatory powers - the mediator systematically facilitates communication between the parties with the aim of enabling the parties themselves to take responsibility for resolving their dispute. Persons sometimes decide very quickly, in the short term, sometimes the opposite: after months, after years, there is no decision made for several reasons. It is implicated to have progressive thinking about conflict resolution based on trust. It can be a change in societies to look at conflicts with another aspect.

\section{Leadership and conflict management. Decisions behind leadership styles.}

\subsection{Nature of conflict - literature review}

Karam et al. state that leadership is one of the most studied phenomenon in management [4]. Personality, the relation of a person to himself or herself, also produces economic effects [5].

Numerous theoretical and practical work has demonstrated the link between transformative leadership and group performance and creativity [6]. Conflict is everywhere. Can be found in human relationships and in business relationships. The businesses involved in the formal conflict are, of course, interested in the effective resolution of the conflict. It is not only a matter of conflict that needs to be resolved, but a solution must also be found to make the best use of the resources of the leaders and to ensure that their solutions not only provide short-term solutions but also, if possible, final solutions.

Recently, Alternative Dispute Resolution (ADR) has become an increasingly effective and popular strategy for conflict resolution. The ADR roster includes such well-known processes as arbitration, mediation, conciliation, and, perhaps, negotiation. These processes can be used to settle existing disputes or to prevent disputes from developing [7]. Litigation is a disadvantage for businesses - the parties lose control, lawyers and the judiciary have power over the timing and procedure of conflict resolution, and as a result, the debate may take years.

Conflict coaching, which trains leaders to manage conflict through integrative training and follow-up, is more effective for empowering leaders to manage conflict within the organization and many different levels of the organizational hierarchy, while mediation, which relies on a balance of power and a dialogue-focused setting, is more effective for individuals on the same level of the organizational power hierarchy to come to their own solution through the help of a mediator [8]. 
The participants in the conflict lose their ability to communicate with each other in the process of resolving the problem. This damages most business relationships and undermines trust and cooperation. In addition, the costs of litigation, court fees, litigation costs and lawyers' fees are significant to settle the conflict. Companies that participate in court proceedings may lose their competitive advantage.

On the other hand, alternative dispute resolution procedures have become increasingly common due to the benefits. Costs are lower, the process is simplier, less formalized, and communication between the parties is more sustainable and managed. If alternative dispute resolution methods are used, the agreement is reached only if both parties agree to voluntarily participate in the mediation procedure. Expressing their own intent on conflict management is a rationalized approach to conflict.

Although there are some remarkable differences between the various ADR procedures, a common feature can be identified: the dispute is mostly determined by the parties involved and the third party (the intermediary) has less power.

While in court cases the court has absolute jurisdiction to resolve the conflict and to enforce the decision, the parties will determine the outcome of the dispute through mediation, of course, in accordance with the rules and applicable law. In alternative dispute resolution, when the result is reached, that is, at the conclusion of the settlement, the parties may take into account a wider range of rules, especially their business interests [9].

Therefore mediation and arbitration are procedures based on interests and rights. The fact that the business interests are taken into account also means that the parties may decide on the result based on their desired future relationship, and not only on the basis of their past behavior.

The settlement of alternative dispute resolution can help to rebuild relationships, restore the original state, establish new relationships, and maintain communication between the parties.

The mediator, the procedure of the mediator is not against the court procedure. The two procedures are linked to the question of enforceability - if the parties of the dispute submit the settlement of the mediation procedure to the competent court with jurisdiction, to include in the decision - enforceability is a common issue, a common matter.

The term conflict has no single meaning [10,11]. Most of the confusion around the definition was created by scientists from different disciplines who are interested in studying conflicts. The literature review of the conflict shows the conceptual complexity of the commonly accepted definition of conflict.

Reviews of the conflict literature show a conceptual sympathy for, but little consensual endorsement of, any generally accepted definition of conflict. There is tremendous variance in conflict definitions that include a range of definitions for specific interests and a variety of general defintions that attempt to be all-inclusive. Conflict can be considered as a breakdown in the standard mechanisms of decision making, so that an individual or group experiences difficulty in selecting an alternative [12]. Research show paths of the negotiation space and negotiation strategies, agreements between nations, firms, and individuals facilitate trade and ensure smooth interaction [13].

\subsection{Leadership styles and conflict management}

In order for an organization to be successful, its employees need to work in harmony to achieve their goals [14].

Starting question, what is leadership? The leader's first responsibility is to define reality. The last is to say thank you. Between the two stages, the leader must become a servant and a debtor. That sums up the progress of an artful leader [15]. 
There are countless theoretical works, writing, curriculum, discussion paper, website on leadership, direction, leadership concepts. It is not easy to determine what leadership means.

Leadership is any management, organizational, and control activity that a person has in relation to at least one additional person.

Different leadership styles are associated with conflict resolution styles. Leaders who are predominantly in the transformative leadership style have adopted integrative and mandatory conflict management styles. Leaders who are mostly transactional style leaders, represent a compromise (unified) conflict management style. While the laissez-faire management style has adopted the avoidance conflict management style [14].

In Rahim's typology, organizational conflict management styles are [12]:

- Integrating

- Obliging

- Compromising

- Dominating

- Avoiding

Leadership styles of leaders in the organization system are:

- Transformational

- Transactional

- Laissez-faire

Saeed and his co-workers consider integrating and obliging as constructive conflict management, while dominating and avoiding styles as destructive conflict management [14].

Their assertions have been confirmed in their study, according to which the transformational leadership style has a positive relationship with a constructive conflict segmentation and a negative connection to this style of leadership in the destructive conflict management style.

There is also a link between transaction management style and compromise conflict management style.

Partial connectivity can be demonstrated by the identification of laissez-faire leadership with a destructive conflict management style. However, the laissez-faire leadership has a negative relationship with constructive conflict management styles.

Examining business alternative dispute resolution, there is a proven relationship between leadership styles and conflict management styles among managers, executives, and in the management of interpersonal (managerial and subordinate) conflicts [14]. Karam et al. state that leadership is one of the most frequently studied phenomenon in the field of management [4]. Identity, a person's sense of self, affects economic outcomes [5].

\section{Data collection}

To analyse more deeper the subject, leaders of companies, legal entities were interviewed about their possible decisions in case of conflict. The profile of the subjects were leaders, businessmen and officials from Pest County and Budapest (registered seats). The tool of the research was a survey, a questionnaire in the subject of leadership styles compared with conflict management styles among the capital and Pest County registered seats companies. 124 leaders were contacted and responded the questions. One of the questions of the study focused in asking about preferred decisions in case of a conflict in the organization, specifically:

1. In case of a conflict of your organization (inter-organizational conflict) which way of conflict resolution is preferred in your decision? AFTER I HAVE TRIED ALL NEGOTIATION WITH THE PARTIES I WILL: 
- Choose to start COURT procedure -court settlement of conflict resolution.

- Choose ARBITRATION - The Arbitral Tribunals are private courts where the parties concerned agree that their arbitration shall be entrusted to the arbitral tribunal designated by the parties, without recourse to ordinary court proceedings.

- Choose MEDIATION - a negotiation facilitated by a neutral third-party who assists the parties in moving to resolution. The neutral has no control over the outcome but controls/directs the process.

- Choose CONCILIATION - The jurisdiction of the conciliation body is to settle the consumer dispute out of court. It is also tasked with attempting to settle the dispute between the parties for the purpose of settling the consumer dispute, in case of ineffectiveness, to make a decision in the matter to ensure the simple, fast, effective and cost-effective enforcement of consumer rights.

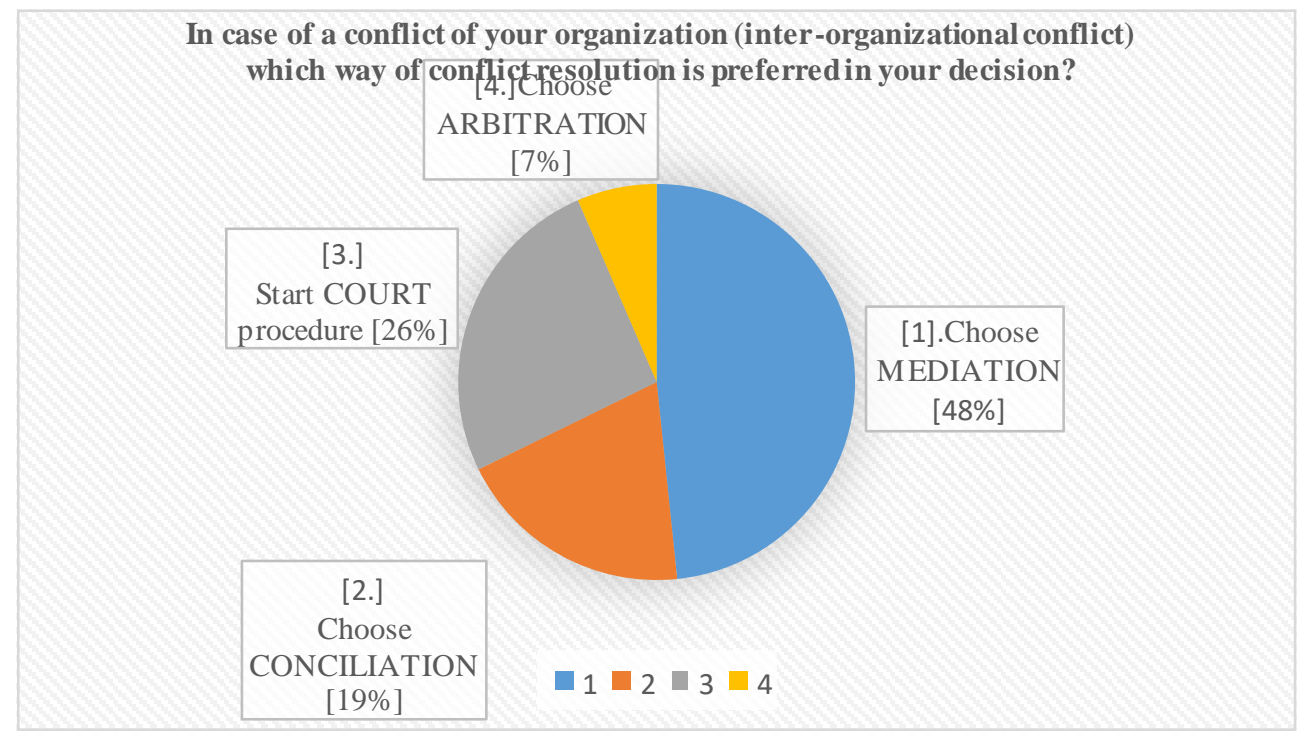

Fig. 1. Identification of differences between methods of conflict resolutions (ADR/Litigation) in Hungary

The $48 \%$ of the participants would choose mediation procedure in case of a conflict between legal entities.

The $26 \%$ of participants would continue the conflict between organizations before court.

The $19 \%$ of the questioned leaders would choose conciliation as a possible way for resolving conflicts.

The remaining $7 \%$ of the responding leaders voted for choosing arbitration if conflict is emerged.

The fact is, that the $74 \%$ of the participants would choose a form of alternative dispute resolution process in total, which confirms the commitment of the members of this sampling to ADR.

The result of the interview indicate that the statement recorded in the title of Ábrahám and Eörsi can be confirmed. Is it bad to litigate? According to the answers of interviewed leaders, the answer can be 'yes' [16]. 


\section{Conclusion}

Conflict management can benefit society, the individual, businesses, focusing on the dynamism of conflict, regarding conflict not only as a negative situation but also as an opportunity. The parties involved in mediation receive support during the mediation process in order to be willing and able to decide in their own case. Mediation is also about enabling the parties to remain owners and leaders of their own case.

Conflict management is one of the ways to achieve peace. In terms of the social meaning of conflict and peace [17], individuals, organizations, workplaces, families, neighbours, states, consumers of different cultures are able to make their own choices through procedural and content tools for alternative dispute resolution, conflict management, and mediation. The socio-moral climate was positively related to innovation. The positive relation between the socio-moral climate and innovation was mediated stepwise through debate and decision comprehensiveness [18-20].

This paper aimed to internationally examine the relationship between leadership decision-making and resolution of conflict. Author is aiming to provide a comprehensive global literature review of leadership decision-making and conflict management. The interview shows that more than half of the respondents opt for alternative dispute resolution.

\section{References}

1. T. Hendel, Leadership style and choice of strategy in conflict management among Israeli nurse managers in general hospitals, Journal of Nursing Management, 13, 1 (2005)

2. K. Celuch, H.J. Bantham, J. C. Kasouf, The role of trust in buyer-seller conflict management, Journal of Business Research. 64, 1082-1088 (2011)

3. Y. Heller, E. Mohlin : Observations on Cooperation, The Review of Economic Studies, 85, 2253-2282 (2017)

4. E.P., Karam, J. Hu, R.B. Davison, M. Juravich, J.D. Nahrgang, S.E. Humphrey, S.D.DeRue: Illuminating the 'Face' of Justice: A Meta-Analytic Examination of Leadership and Organizational Justice, Journal of Management Studies, 56,134 (2019)

5. G. Akerlof, R.E. Kranton, Economics and Identity The Quarterly Journal of Economics. 115, 715 (2000)

6. K. Boies, J. Fiset, H. Gill : Communication and trust are key: Unlockingthe relationship between leadership and team performance and creativity The Leadership Quarterly 26, 1080 (2015)

7. J. K. Lieberman\&J. F. Henry, Lessons from the Alternative Dispute Resolution Movement, The University of Chicago Law Review, 53 424-439 (1986)

8. T. Carden, Workplace conflict strategies : Conflict coaching versus mediation, Journal of Conflict Management, 6, 1 (2018)

9. J. Bercovitch \& R.Jackson Negotiation or Mediation?: An Exploration of Factors Affecting the Choice of Conflict Management, International Conflict Negotiation Journal, 17, 59-77. (2001)

10. C.F. Fink, Some conceptual difficulties in the theory of social conflict. Journal of Conflict Resolution, XII, 413-458 (1968)

11. A. Caputo, G. Marzi, M.M. Pellegrini, R. Rialti, Conflict management in family businesses. A bibliometric analysis and systematic literature review. International Journal of Conflict Management, 29, 519 (2018) 
12. A.M. Rahim, Managing Conflict in Organizations, (4th ed.Tylor \& Francis, 2011)

13. U.F Ott, P. N. Ghauri Brexit negotiations: From negotiation space to agreement zones. Journal of International Business Studies 1-13 (2018)

14. T. Saeed, S. Almas, M. Anis-ul-Haq, G. Niazi: Leadership styles: relationship with conflict management styles. International Journal of Conflict Management, 25, 214225 (2014)

15. M. De Pree, Leadership is an Art. (Currency Book Doubleday, New York 2004)

16. Z. Ábrahám, M. Eörsi, Pereskedni rossz! -Mediáció: a szelíd konfliktuskezelés-It is bad to litigate! Mediation-the gentle conflict management. (Budapest, Minerva, 2003)

17. J.P. Lederach, Proposing for Peace Across Cultures (Syracuse University Press, 1995)

18. S. Seyr, A. Vollmer.: Socio-moral climate, debate, and decision comprehensiveness interplay for team innovation. International Journal of Conflict Management, 25, 105123 (2014)

19. G. Calabresi, The Costs of Accidents, a legal and economic analysis, (Yale University Press, 1970)

20. H. W. Nies, Rambo, Lawyering: The Need for Civility in Civil Litigation IDEA 1, 1-2. (1991) 